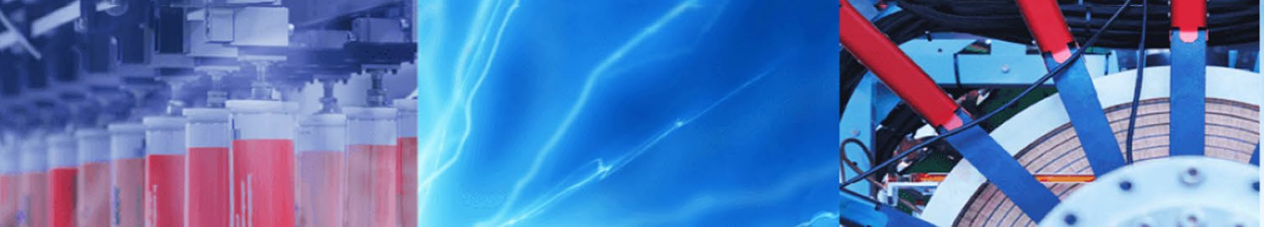

Research Article

\title{
Taguchi method-based optimization of extinguishing parameters for minimizing the extinction time of gaseous fires
}

\author{
Haidar Ibrahim ${ }^{1}$ ] Jagannadha Rao Patruni ${ }^{1}$
}

Received: 4 September 2019 / Accepted: 5 November 2019 / Published online: 9 November 2019

(c) Springer Nature Switzerland AG 2019

\begin{abstract}
In the present work, the extinguishing parameters influencing the dry chemical powder system performance were analyzed and optimized using Taguchi design for minimizing the extinction time of small-scale vertical and horizontal gaseous fires. The system-related parameters include the release pressure $(0.2 \mathrm{MPa}, 0.3 \mathrm{MPa}$, and $0.4 \mathrm{MPa})$, the suppression angle (horizontal, diagonal, and vertical), and the release distance $(50 \mathrm{~cm}, 75 \mathrm{~cm}$, and $100 \mathrm{~cm}$ ). The extinguishing tests were carried out in a lab-scale local application system. In this study, the magnesium hydroxide powder $\left(\mathrm{Mg}(\mathrm{OH})_{2}\right)$ was used as an extinguishing agent. The analysis of experimental results showed that the optimum extinguishing conditions for small vertical and horizontal fires were at the release pressure $(0.4 \mathrm{MPa})$, the suppression angle (vertical), and the release distance $(50 \mathrm{~cm})$. The analysis of variance indicated that the percentage contribution of extinguishing parameters on vertical fire extinction time was in the following order: suppression angle $(44.69 \%)>$ the release distance $(39.04 \%)>$ the release pressure $(2.63 \%)$. While the order in case of the horizontal fire was as follows: the release distance $(66.00 \%)>$ the release pressure $(17.65 \%)>$ suppression angle $(12.34 \%)$. The confirmatory tests showed that the extinction time at optimal parameters was lower than that achieved in all other experimental tests.
\end{abstract}

Keywords Dry chemical powder · Extinguishment · Suppression angle · Jet fire · Taguchi design

\section{Introduction}

Jet fires are often reported as the recurrent fires in gas industries. Jet fires occur due to the pressurized leaks of gas and reach full intensity almost immediately [1]. Therefore, such fires pose significant hazards to gas facilities, which handle highly pressurized flammable hydrocarbons. Gomez et al. have surveyed accident databases in industrial installations. The results revealed that the liquefied petroleum gas (LPG) was the most frequently involved fuel in jet fire accidents [2]. There have been many catastrophic fires in the past with huge loss of personnel and property such as Piper Alpha accident in 1988 [3], fire at Passos Refinery in 1998, and massive fire in Bombay process platform in 2005 [4]. Due to the frequent occurrence of gaseous fire accidents, the researchers have directed their efforts to find out an effective fire suppression process for such LPG fires. Efficient suppression could rapidly limit the fire and minimize the severity of consequences. The halon based extinguishing agents were phased out because they damage the ozone layer. Therefore, the development of new efficient extinguishing processes is great of importance [5].

Many fire suppression agents were widely employed to replace the halon such as water, foam, dry chemical powders, and clean gaseous systems. The clean gaseous systems such as inert nitrogen and argon are considered the safest and cleanest extinguishing agents. However, the gaseous systems are less effective in extinguishing of hydrocarbon fires in comparison with dry chemical

$\triangle$ Haidar Ibrahim, haider-ibraheem@hotmail.com | ${ }^{1}$ Department of Chemical Engineering, College of Engineering (A), Andhra University, Visakhapatnam, Andhra Pradesh 530003, India. 
powders. Therefore, dry chemical powders such as sodium bicarbonate $\left(\mathrm{NaHCO}_{3}\right)$, potassium bicarbonate $\left(\mathrm{KHCO}_{3}\right)$, and mono ammonium phosphate $\left(\mathrm{NH}_{4} \mathrm{H}_{2} \mathrm{PO}_{4}\right)$ were the most efficient agents to replace the halon. Recently, many studies have been conducted to improve the suppression efficiency of available commercial powders. The high suppression efficiency can be achieved by improving the powders' properties or the extinguishing system. Ni et al. have fabricated a new suppressant powder consisting of sodium bicarbonate nanoparticles $\mathrm{NaHCO}_{3}$ and zeolite 13X [6]. Once again, $\mathrm{Ni}$ et al. synthesized novel nanocomposites consisting of zeolites and a gaseous agent (2-bromo-3,3,3-trifluoropropene) [7]. Kuang et al. developed a new K-powder based on potassium bicarbonate powders, which showed a higher suppression efficiency than commercial powders [8]. This was due to the special microstructure, chemical composition, and radiation effects on the suppression mechanisms. Yuan and his team [9] manufactured a new powder of magnesium hydroxide $\left(\mathrm{Mg}(\mathrm{OH})_{2}\right)$ modified with DOPO-VTS. The 9,10-dihydro-9-oxygen mixed-10-phosphaphenanthrene-10-oxide (DOPO) is a phosphorusbased flame retardant, while vinyl trimethoxy silane (VTS) is a coupling agent. All the prepared suppressants exhibited superior performance to commercial powders because they have smaller particle size, larger surface area, more regular shape, and better chemical inhibition mechanism than that of commercial powders.

The prior works have mainly focused to improve the powders' properties such as chemical composition, particle size, and microstructure to enhance their extinguishing efficiency. While the extinguishing parameters related to the suppression system itself were not addressed adequately despite their expected effective role on fire extinction performance. Therefore, in this study, the influence of controllable extinguishing parameters on the performance of the dry chemical powder system was optimized to minimize the fire extinction time of vertical and horizontal gaseous fires. The controllable factors involved the release pressure, the suppression angle, and the release distance. Some earlier works $[10,11]$ have investigated the pressure influence in single-factor experiments and revealed that the fire extinguishing time decreases with an increase in the release pressure. The impact of the suppression angle was not assessed in the dry chemical powder system. Nevertheless, this parameter was analyzed in other fire suppression systems such as the liquid nitrogen suppression system [12] and water mist system [13]. However, all these works were single-effect studies in which only one factor was investigated while the others remained constant. So, the combined and main effects of variables were not sufficiently considered and the optimum parameters to obtain the desired response of the system could not be identified properly.

The statistical design of experiments provides a more simple and efficient tool to optimize several operational variables. Taguchi method has been proved as a powerful experimental design technique to produce a high-quality performance at low cost and time because it allows the optimization with fewer experimental runs [14]. Taguchi technique uses the design of orthogonal array (OA) to assign the selected parameters and levels for experiments [15].

In the current research, the optimization of extinguishing parameters, including the release pressure, the suppression angle, and the release distance was investigated to reduce the extinction time of the small-scale vertical and horizontal fire. A Taguchi OA was employed to design the experimental tests. The experiments were carried out in a lab-scale extinguishing system. LPG was employed as a fuel to create small-scale gaseous jet flames. The $\mathrm{Mg}(\mathrm{OH})_{2}$ powder was applied as the extinguishing agent in all experiments. We have used $\mathrm{Mg}(\mathrm{OH})_{2}$ powders since it is cheap and available. The percentage contribution of each factor on extinction time was evaluated. Furthermore, the confirmation tests were also performed at optimal parameters.

\section{Experimental}

\subsection{Dry chemical powder extinguishing system}

A lab-scale dry chemical suppression system was built as shown in Fig. 1.

LPG was adopted as a gaseous fuel for all experiments with a fixed mass flow rate of $0.00024 \mathrm{~kg} / \mathrm{s}$. The LPG fire was created by a tube burner with $15 \mathrm{~cm}$ height and $1 \mathrm{~cm}$ internal diameter. At the burner exit, a circular brass nozzle was fixed with a diameter of $0.6 \mathrm{~cm}$ through which the LPG flow was jetted. The burner can be positioned vertically or horizontally to create a small-scale vertical or horizontal LPG flame, respectively. The LPG flame was allowed to burn free to reach a steady-state before applying the suppressant. Table 1 lists the characteristics of the LPG flame used in all experimental runs. Calculations of LPG exit velocity, source Froude number, and Reynolds number are presented in "Appendix". The Froude number $<1$ demonstrating that the fire was dominant-driven rather than buoyancy. Besides, the Reynolds number was relatively high $(\operatorname{Re}>4000)$, which means that the flame was on the turbulent regime.

High-pressurized nitrogen gas was used as a carrier gas of the extinguishing agent. The nitrogen gas cylinder was pressurized of about $17 \mathrm{MPa}$ and equipped with a pressure 
Fig. 1 Schematic illustration of the experimental extinguishing system

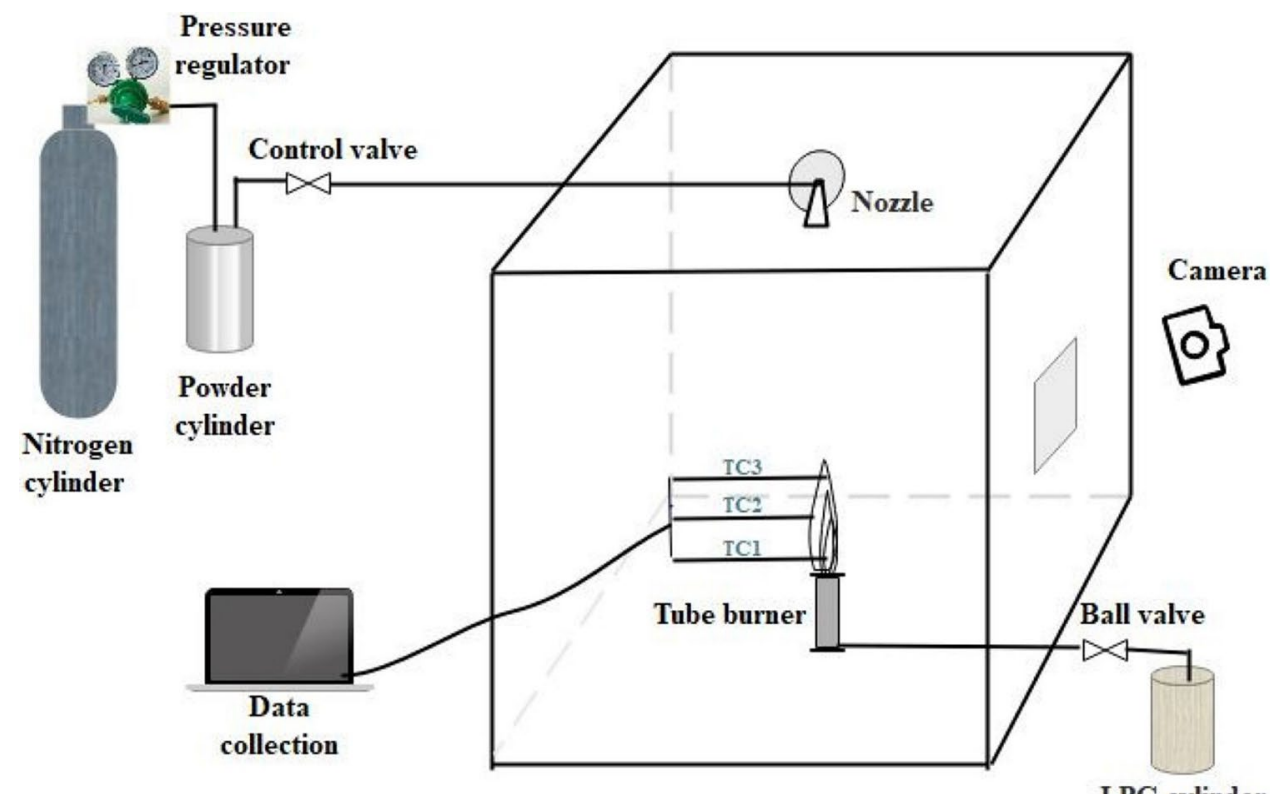

LPG cylinder
Table 1 LPG flame characteristics

\begin{tabular}{lllll}
\hline $\begin{array}{l}\text { Mass flow } \\
\text { rate }(\mathrm{kg} / \mathrm{s})\end{array}$ & $\begin{array}{l}\text { Exit velocity } \\
(\mathrm{m} / \mathrm{s})\end{array}$ & $\begin{array}{l}\text { Thermal } \\
\text { power }(\mathrm{kW})\end{array}$ & $\begin{array}{l}\text { Froude } \\
\text { number }\end{array}$ & $\begin{array}{l}\text { Reynolds } \\
\text { number }\end{array}$ \\
\hline 0.00024 & 3.93 & 11.1 & 262 & 6913 \\
\hline
\end{tabular}

Table 2 The main properties of the magnesium hydroxide powder

\begin{tabular}{ll}
\hline Property & Value \\
\hline Purity $(\%)$ & $>99$ \\
Moisture & $\leq 0.2$ \\
Average particle size $(\mu \mathrm{m})$ & 12 for lengthways \\
& and 7 for trans- \\
& verse \\
Bulk density $(\mathrm{g} / \mathrm{mL})$ & 0.3 \\
Loss in ignition at $800^{\circ} \mathrm{C}(\%)$ & $30-32$ \\
\hline
\end{tabular}

regulator to control the downstream pressure. A nitrogen gas flowmeter was also mounted to measure the flow rate of nitrogen gas at various release pressure values $(0.2 \mathrm{MPa}$, $0.3 \mathrm{MPa}$, and $0.4 \mathrm{MPa}$ ).

The powder was placed into a small designed container with $4.3 \mathrm{~cm}$ internal diameter and $14.5 \mathrm{~cm}$ height. The properties of the $\mathrm{Mg}(\mathrm{OH})_{2}$ extinguishing agent are presented in Table 2.

A conical nozzle with a spray angle of about $34^{\circ}$ and $1.8 \mathrm{~cm}$ base diameter was used to discharge the powder onto the fire. Three ball control valves were installed to cut off immediately the flow of nitrogen, powder, and LPG gas when the fire was completely extinguished. To meet the experimental requirements, the suppression angle can be adjusted to be horizontal, vertical, or diagonal, while the release distance of the nozzle can also be set at $50 \mathrm{~cm}$, $75 \mathrm{~cm}$, or $100 \mathrm{~cm}$. Figure 2 illustrates the configurations of vertical, diagonal, and horizontal suppression angles for small vertical and horizontal LPG fire.

The changes in temperature during the suppression process were monitored and recorded by three K-type thermocouples (TC-1, TC-2, and TC-3) with Arduino (Mega 2560) connected to the computer. Arduino is a microcontroller operated by Arduino IDE software, which used for writing, compiling, and uploading the programming code into the Arduino module. The temperature values measured by thermocouples transfer to Arduino as an equivalent voltage. As per the programming code, the Arduino converts the voltage value to digital temperature readings. The extinguishing processes were captured using a camera to measure the extinction time and observe the timebased flame behavior.

\subsection{Design of experiment}

The effects of various suppression parameters were analyzed in terms of extinction time using Taguchi experimental design. As mentioned previously, the objective of this study is to minimize the fire extinction time. Therefore, the smallest extinguishing time was set as the desired response. The controllable factors affecting the performance of the dry chemical powder system were selected to be the release pressure, the suppression angle, the release distance. In this present experimental work, each controllable factor was set at three levels as presented in 


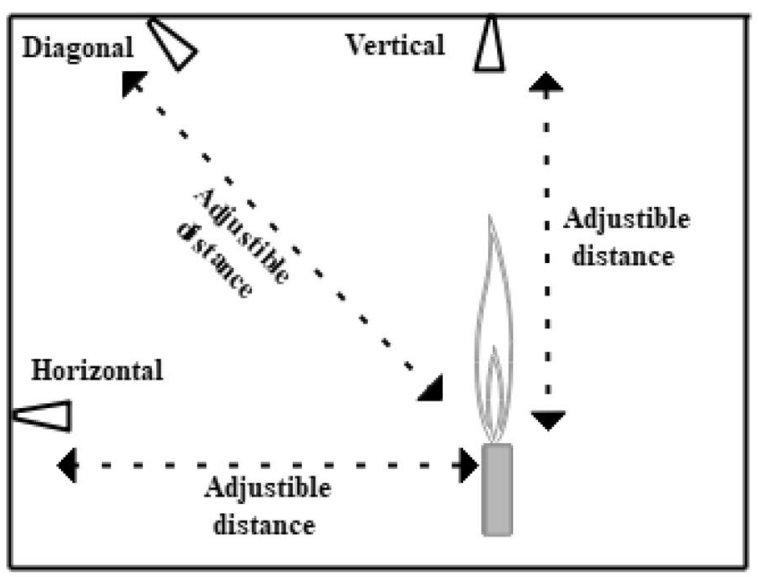

(a) Vertical fire.

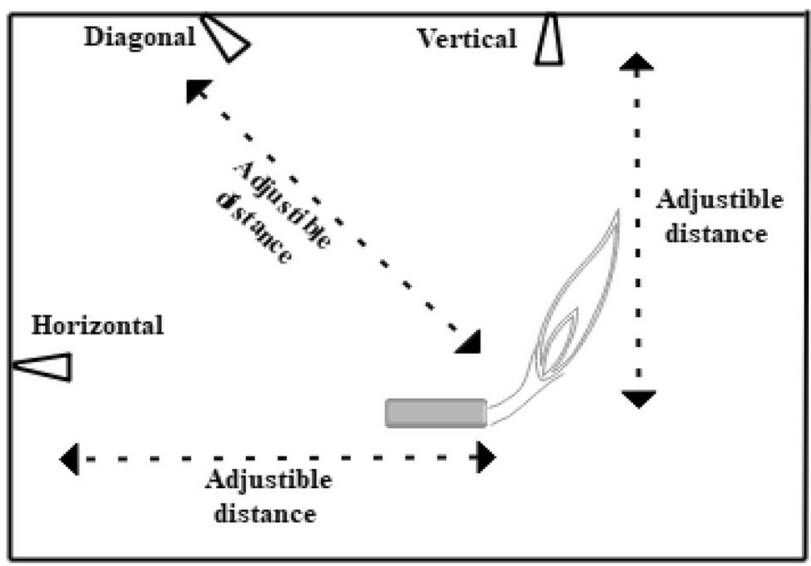

(b) Horizontal fire.

Fig. 2 Various suppression configurations for small vertical and horizontal LPG fire

Table 3. The ranges of suppression parameters were chosen based on the preliminary tests.

After that, the appropriate $O A$ is selected to design the experiments. There are 18 standard $\mathrm{OA}_{\mathrm{s}}$ were formulated by Taguchi to use them in the experimental design [16]. Concerning to this work, the experimental design for three parameters with three levels can be conducted using either L9 or L27. In this research, we have chosen L9 OA because it reduces the number of tests, which minimizes the cost and the time needed. Table 4

Table 3 Extinguishing parameters and their levels

\begin{tabular}{llll}
\hline Controllable parameter & Level & & \\
\cline { 2 - 4 } & Level 1 & Level 2 & Level 3 \\
\hline Release pressure (P), MPa & 0.2 & 0.3 & 0.4 \\
Suppression angle (SA) & Horizontal & Diagonal & Vertical \\
Release distance (D), cm & 50 & 75 & 100 \\
\hline
\end{tabular}

presents the assignment of various factors and levels in the OA.

The designed experimental runs were then conducted and the corresponding response (extinction time) was recorded. All experiments were repeated twice and the average extinction time was computed. After that, the collected data have to be analyzed to identify the optimum setting parameters of the dry chemical powder system. Signal-to-Noise $(\mathrm{S} / \mathrm{N})$ ratios analysis and analysis of variance (ANOVA) were employed to evaluate the process performance.

$\mathrm{S} / \mathrm{N}$ ratios are used to measure the quality characteristic deviates from the desired value $[17,18]$. The research aim was to minimize the extinction time of the suppression system; so, it was decided to select the $\mathrm{S} / \mathrm{N}$ ratio related to the smaller is the better performance and was calculated as per Eq. 1:

$S / N=-10 \log \left(\frac{1}{n} \sum_{i=1}^{n} T_{i}^{2}\right)$

where $n$ represents the total number of replications of each test run and $T_{i}$ represents the extinction time measured in the replication experiment $i$ carried out under the same experimental conditions of each test run.

The analysis of mean (ANOM) for $\mathrm{S} / \mathrm{N}$ ratios was then used to identify the optimal extinguishing parameters. To obtain the optimal parameters, the greater $\mathrm{S} / \mathrm{N}$ ratio corresponds to the better performance (the smaller variance).

ANOVA is a statistical measure to determine the percentage contribution $\left(C_{i}\right)$ of each controllable parameter on the desired performance $[19,20]$.

Once the optimal levels of the design parameters have been determined, the final step is to predict and verify the improvement of the response at optimal

Table 4 Test runs using L9 OA

\begin{tabular}{lllc}
\hline $\begin{array}{l}\text { Experi- } \\
\text { mental } \\
\text { run }\end{array}$ & $\begin{array}{l}\text { Release pres- } \\
\text { sure (P), MPa }\end{array}$ & Suppression angle (SA) & $\begin{array}{l}\text { Release } \\
\text { distance (D), } \\
\text { cm }\end{array}$ \\
\hline 1 & 0.2 & Horizontal (H) & 50 \\
2 & 0.2 & Diagonal (D) & 75 \\
3 & 0.2 & Vertical (V) & 100 \\
4 & 0.3 & Horizontal (H) & 75 \\
5 & 0.3 & Diagonal (D) & 100 \\
6 & 0.3 & Vertical (V) & 50 \\
7 & 0.4 & Horizontal (H) & 100 \\
8 & 0.4 & Diagonal (D) & 50 \\
9 & 0.4 & Vertical (V) & 75 \\
\hline
\end{tabular}


levels. The predicted optimum $\mathrm{S} / \mathrm{N}$ ratio can be estimated by Eq. 2, which was discussed by Yang and Tarng [17]:

$S / N_{\text {pred }}=\mu_{m}+\sum_{i=1}^{N}\left(\bar{\mu}_{i}-\mu_{m}\right)$

where $\mu_{\mathrm{m}}$ represents the overall mean $\mathrm{S} / \mathrm{N}$ ratio and $\bar{\mu}_{\mathrm{i}}$ represents the mean $\mathrm{S} / \mathrm{N}$ ratio at the optimal level $\mathrm{i}$.

\section{Results and discussion}

\subsection{Analysis of $\mathrm{S} / \mathrm{N}$ ratio}

The presented experimental runs in Table 4 were conducted and then average extinction time and corresponding $\mathrm{S} / \mathrm{N}$ ratio for both vertical and horizontal fires are recorded in Tables 5 and 6 , respectively. The $\mathrm{S} / \mathrm{N}$ ratio was calculated using Eq. 1 for each trial conditions for the extinction time.

The mean $\mathrm{S} / \mathrm{N}$ ratio of each level for each factor was calculated as shown in Table 7. Similarly, the mean extinction
Table 5 Vertical fire extinction time and corresponding $\mathrm{S} / \mathrm{N}$ ratio
Table 6 Horizontal fire extinction time and corresponding $\mathrm{S} / \mathrm{N}$ ratio
Table 7 Response table for mean extinction time and mean $\mathrm{S} / \mathrm{N}$ ratios for vertical fire

\begin{tabular}{llllllr}
\hline Run & Levels & & & Extinction time $(\mathrm{s})$ & $\mathrm{S} / \mathrm{N}$ & \multicolumn{1}{c}{$\mathrm{S} / \mathrm{N}^{2}$} \\
\hline 1 & 0.2 & $\mathrm{H}$ & 50 & 0.23 & 12.76 & 162.82 \\
2 & 0.2 & $\mathrm{D}$ & 75 & 0.26 & 11.70 & 136.89 \\
3 & 0.2 & $\mathrm{~V}$ & 100 & 0.28 & 11.06 & 122.32 \\
4 & 0.3 & $\mathrm{H}$ & 75 & 0.27 & 11.37 & 129.28 \\
5 & 0.3 & $\mathrm{D}$ & 100 & 0.35 & 09.12 & 83.17 \\
6 & 0.3 & $\mathrm{~V}$ & 50 & 0.14 & 17.00 & 289.00 \\
7 & 0.4 & $\mathrm{H}$ & 100 & 0.27 & 11.37 & 129.28 \\
8 & 0.4 & $\mathrm{D}$ & 50 & 0.26 & 11.70 & 136.89 \\
9 & 0.4 & $\mathrm{~V}$ & 75 & 0.18 & 14.90 & 222.01 \\
Total & & & & 2.24 & 110.98 & 1411.66 \\
\hline
\end{tabular}

Correction factor $(C F)=(110.98)^{2} / 9=1368.5$

Total sum of squares $\left(\mathrm{SS}_{\mathrm{t}}\right)=1411.66-1368.5=43.16$

\begin{tabular}{lllllrr}
\hline Run & Levels & & & Extinction time $(\mathrm{s})$ & $\mathrm{S} / \mathrm{N}$ & \multicolumn{1}{c}{$\mathrm{S} / \mathrm{N}^{2}$} \\
\hline 1 & 0.2 & $\mathrm{H}$ & 50 & 0.27 & 11.37 & 129.28 \\
2 & 0.2 & $\mathrm{D}$ & 75 & 0.43 & 7.33 & 53.73 \\
3 & 0.2 & $\mathrm{~V}$ & 100 & 0.49 & 6.20 & 38.44 \\
4 & 0.3 & $\mathrm{H}$ & 75 & 0.25 & 12.04 & 144.96 \\
5 & 0.3 & $\mathrm{D}$ & 100 & 0.80 & 1.94 & 3.76 \\
6 & 0.3 & $\mathrm{~V}$ & 50 & 0.17 & 15.39 & 236.85 \\
7 & 0.4 & $\mathrm{H}$ & 100 & 0.37 & 8.64 & 74.65 \\
8 & 0.4 & $\mathrm{D}$ & 50 & 0.17 & 15.39 & 236.85 \\
9 & 0.4 & $\mathrm{~V}$ & 75 & 0.20 & 13.98 & 195.44 \\
Total & & & & 3.15 & 92.28 & 1113.96 \\
\hline
\end{tabular}

Correction factor $(C F)=(92.28)^{2} / 9=946.18$

Total sum of squares $\left(\mathrm{SS}_{\mathrm{t}}\right)=1113.96-946.18=167.78$

\begin{tabular}{|c|c|c|c|c|c|c|}
\hline \multirow{2}{*}{$\begin{array}{l}\text { Parameter/ } \\
\text { level }\end{array}$} & \multicolumn{3}{|c|}{ Mean extinction time } & \multicolumn{3}{|c|}{ Mean $\mathrm{S} / \mathrm{N}$ ratio } \\
\hline & Level 1 & Level 2 & Level 3 & Level 1 & Level 2 & Level 3 \\
\hline$P$ & 0.257 & 0.253 & 0.237 & 11.84 & 12.50 & 12.66 \\
\hline SA & 0.257 & 0.290 & 0.200 & 11.83 & 10.84 & 14.32 \\
\hline D & 0.210 & 0.237 & 0.300 & 13.82 & 12.66 & 10.52 \\
\hline
\end{tabular}


time for each factor at each level was also calculated as listed in Table 8.

The mean extinction time and mean $\mathrm{S} / \mathrm{N}$ ratio response graphs were plotted at different levels for various control parameters as shown in Figs. 3, 4 and 5.

The greatest mean $\mathrm{S} / \mathrm{N}$ ratio for each factor represents the optimal level of that factor. From Figs. 3, 4 and 5, the optimal extinguishing parameters for both fires were determined as the release pressure of $0.4 \mathrm{MPa}$ (level 3 ), vertical suppression (level 3 ), and the release distance of $50 \mathrm{~cm}$ (level 1).
The percentage contribution of each parameter towards the fire extinction time was calculated using ANOVA. The ANOVA results of fire extinction time for both fires are presented in Tables 9 and 10.

ANOVA results for vertical fire extinguishing in Table 9 showed that the suppression angle, the release distance, and release pressure are affecting the extinction time by $44.69,39.04$, and $2.63 \%$, respectively.

From Table 10, the order of percentage contributions of the parameters on the horizontal fire extinction

Table 8 Response table for mean extinction time and mean $\mathrm{S} / \mathrm{N}$ ratios for horizontal fire

\begin{tabular}{llllllrr}
\hline \multirow{2}{*}{$\begin{array}{l}\text { Parameter/ } \\
\text { level }\end{array}$} & \multicolumn{2}{l}{ Mean extinction time } & & \multicolumn{3}{l}{ Mean S/N ratio } \\
\cline { 2 - 3 } & Level 1 & Level 2 & Level 3 & & Level 1 & Level 2 & Level 3 \\
\hline P & 0.399 & 0.402 & 0.247 & & 8.30 & 9.79 & 12.67 \\
SA & 0.297 & 0.467 & 0.287 & & 10.68 & 8.22 & 11.86 \\
D & 0.203 & 0.293 & 0.553 & & 14.05 & 11.12 & 5.59 \\
\hline
\end{tabular}

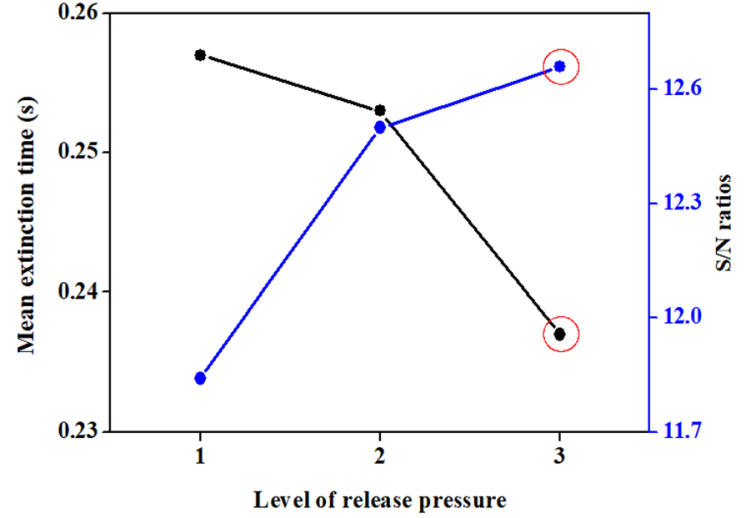

(a) Vertical fire.

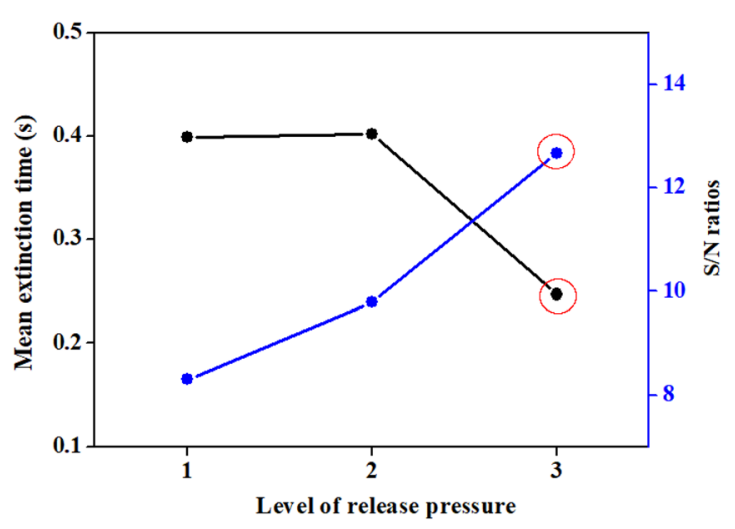

(b) Horizontal fire.

Fig. 3 The influence of release pressure

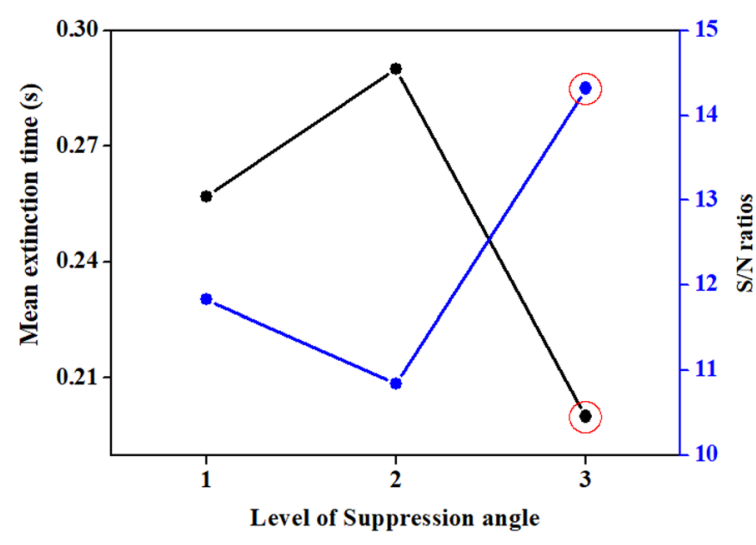

(a) Vertical fire.

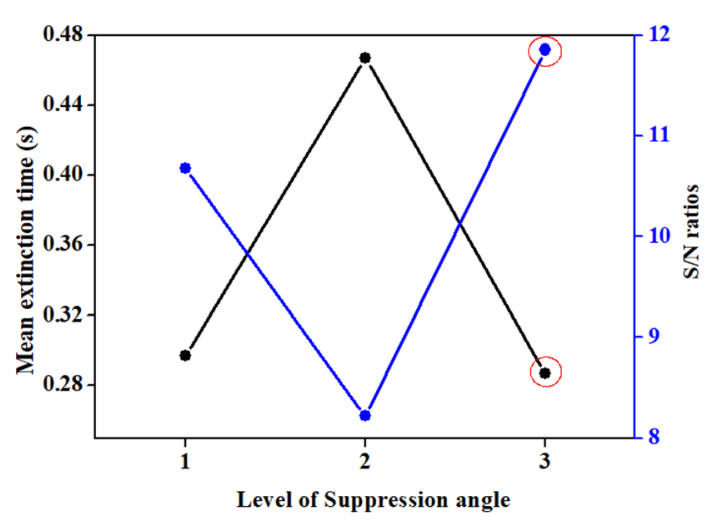

(b) Horizontal fire.

Fig. 4 The influence of suppression angle 


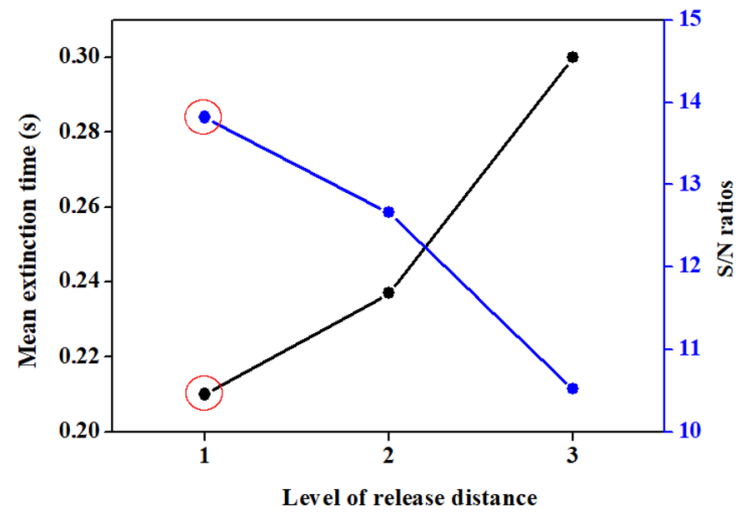

(a) Vertical fire.

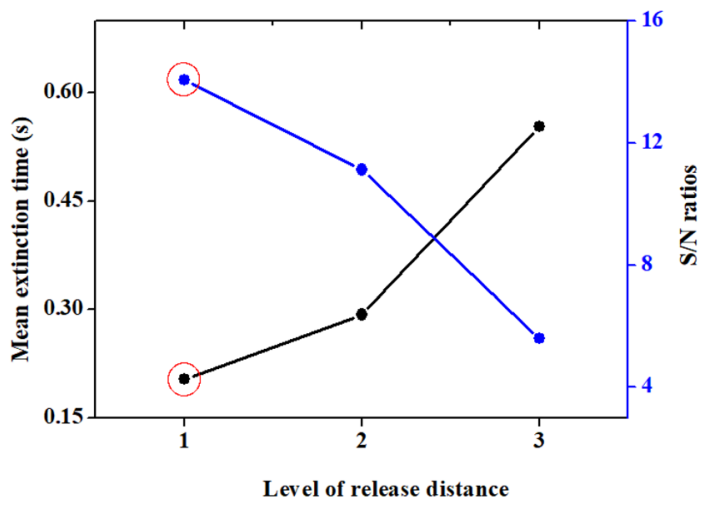

(b) Horizontal fire.

Fig. 5 The influence of release distance

Table 9 ANOVA for vertical fire extinction time and percentage contribution

\begin{tabular}{lclcc}
\hline Factor & Sum of squares & DOF & Mean square & \multicolumn{1}{c}{ C\% } \\
\hline P & 1.13 & 2 & 0.565 & 2.63 \\
SA & 19.29 & 2 & 9.645 & 44.69 \\
D & 16.85 & 2 & 8.425 & 39.04 \\
Error & 5.89 & 2 & 2.945 & 13.64 \\
Total & 43.16 & 8 & 21.58 & 100 \\
\hline
\end{tabular}

Table 10 ANOVA for horizontal fire extinction time and percentage contribution

\begin{tabular}{lclll}
\hline Factor & Sum of squares & DOF & Mean square & C\% \\
\hline P & 29.61 & 2 & 14.81 & 17.65 \\
SA & 20.7 & 2 & 10.35 & 12.34 \\
D & 110.73 & 2 & 55.37 & 66 \\
Error & 6.74 & 2 & 3.37 & 4.01 \\
Total & 167.78 & & 83.9 & 100 \\
\hline
\end{tabular}

time was as follows: the release distance $(66.00 \%)>$ the release pressure $(17.65 \%)$ > suppression angle (12.34\%).

It can be found out that the release pressure and distance has a higher impact on the extinction time of horizontal fire than that of vertical fire. On the contrary, the suppression angle has a greater influence on vertical fire suppression time in comparing with the horizontal fire.

\subsection{Confirmatory experiments}

The $\mathrm{S} / \mathrm{N}$ ratio at optimum parameters was predicted using Eq. 2 for the extinction time of both fires. Then, the confirmatory experiments were carried out under the optimized conditions and compared with predicted values as
Table 11 Confirmatory experiments for extinction time

\begin{tabular}{|c|c|c|c|c|}
\hline & \multicolumn{4}{|c|}{ Confirmatory experiments } \\
\hline & \multicolumn{2}{|l|}{ Vertical fire } & \multicolumn{2}{|c|}{ Horizontal fire } \\
\hline & Prediction & Experiment & Prediction & Experiment \\
\hline Parameter level & $A 3, B 3, D 1$ & $A 3, B 3, D 1$ & $A 3, B 3, D 1$ & $A 3, B 3, D 1$ \\
\hline $\begin{array}{l}\text { Extinction time } \\
(\mathrm{s})\end{array}$ & - & 0.133 & - & 0.165 \\
\hline $\mathrm{S} / \mathrm{N}$ ratio & 16.15 & 17.52 & 18.08 & 15.65 \\
\hline
\end{tabular}

shown in Table 11. The results showed that extinction time at optimal parameters $(0.133 \mathrm{~s}$ for vertical fire and $0.165 \mathrm{~s}$ for horizontal fire) was lower than that of all test trials.

From Table 5, the minimum vertical fire extinction time was obtained by trial $6(0.14 \mathrm{~s})$. From Table 11, the vertical fire extinction time at optimal parameters was $0.133 \mathrm{~s}$, which was $5 \%$ lower than the minimum time obtained in Table 5.

From Table 6, the minimum horizontal fire extinction time was obtained by trials 6 and $9(0.17 \mathrm{~s})$. From Table 11, the horizontal fire extinction time at optimal parameters was $0.165 \mathrm{~s}$, which was $2.94 \%$ lower than the minimum time obtained in Table 6 .

In addition, from Table 11, the experimental values deviate from prediction values by $8.48 \%(15.65-18.08)$ for vertical fire and by $15.53 \%$ (17.52-16.15) for horizontal fire. These comparisons and discussions confirm that there was a small reduction in fire extinction time, which means that the extinguishing process was slightly improved.

Figure 6 displays the typical images of the suppression process of LPG fire by applying the optimal settings of parameters in the confirmatory experiment.

From snapshots, it is clear that the flame was flashed and expanded after the discharge of the powder agent due to the airflow stimulation and enhancement of the 
Fig. 6 The typical snapshots of gaseous fire extinguishing process under optimum parameters

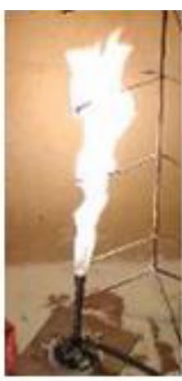

0s

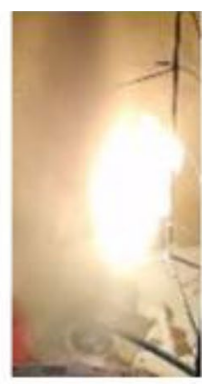

0.05

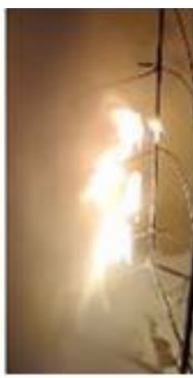

0.083

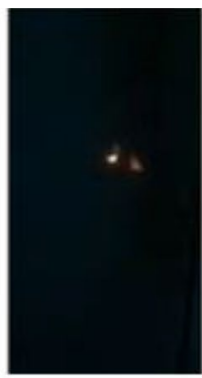

0.116

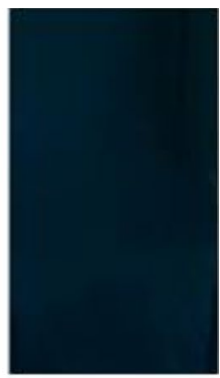

0.133

\section{(a) Vertical fire}

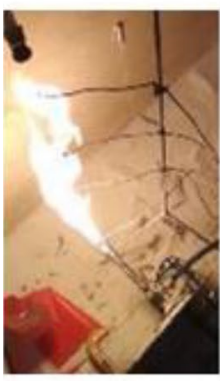

Os

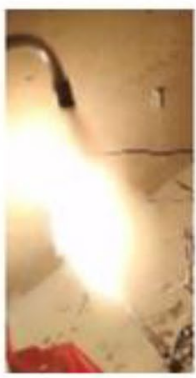

0.033

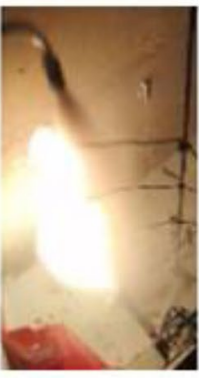

0.066

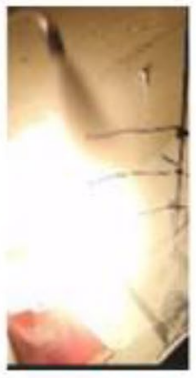

0.099

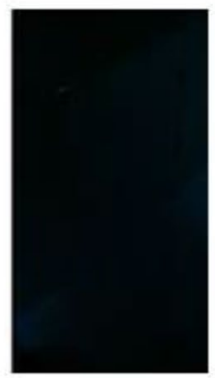

0.165

(b) Horizontal fire

burning process in the flame zone, which exerted by the powder stream.

The temperature histories during the suppression process for both fires were also measured. Figure $7 \mathrm{dem}$ onstrates the temperature variations during the fire extinguishing for the vertical and horizontal fire under optimum parameters in the confirmatory test.

At first, the temperature increased up to relatively stable temperature, which was about $700^{\circ} \mathrm{C}$. After the addition of the extinguishing agent, it can be noticed that the flame temperature slightly increased for a short period. This may due to the flow of nitrogen gas/powder mixture, which stimulated the oxidizing agents around the combustion zone and improved the burning process. After that, the fire was extinguished under the continuous application of the extinguishing agent and the temperature started to decrease to room temperature.

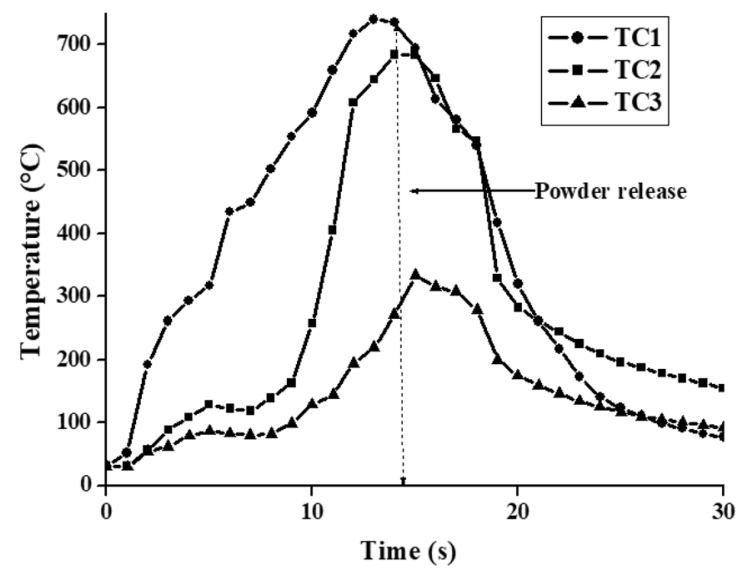

(a) Vertical Fire

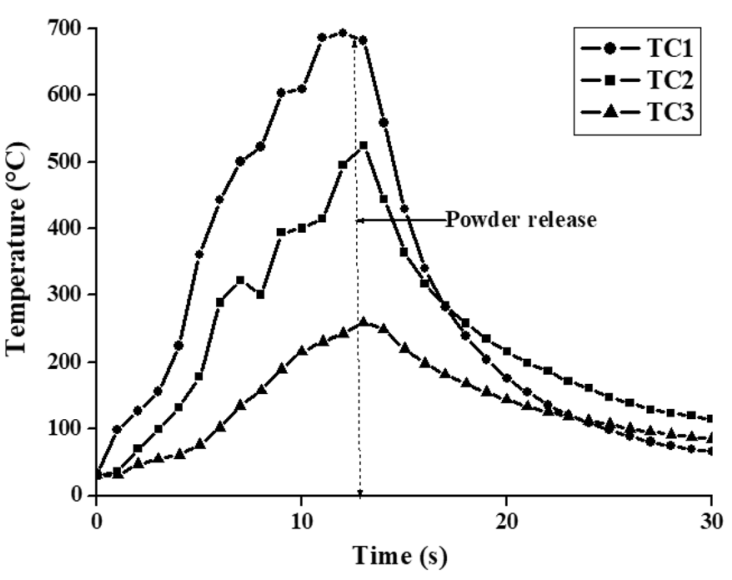

(b) Horizontal Fire

Fig. 7 The temperature variations during the extinguishing process under optimum parameters 
However, the temperature curves showed that the temperature reduction rates varied from vertical fire to horizontal fire. In the case of vertical fire, the TC1 temperature (lower part of the flame) declined from 733 to $408^{\circ} \mathrm{C}$ after $5 \mathrm{~s}$ of powder application (temperature reduction rate $=65^{\circ} \mathrm{C} / \mathrm{s}$ ). On another hand, for horizontal fire, the TC1 temperature dropped from 688 to $259^{\circ} \mathrm{C}$ after $5 \mathrm{~s}$ of powder application (temperature reduction rate $=85^{\circ} \mathrm{C} / \mathrm{s}$ ). The reason may be that the extinction time of the vertical fire was less (less powder discharge duration) than that of horizontal fire (longer powder discharge duration). Therefore, the thermocouples maintained high-temperature values and then dropped slowly to reach the surrounding environment temperature.

In this study, the experimental extinguishing tests indicated that the horizontal gaseous fire was harder to extinguish than vertical gaseous fire. This could be ascribed to that the effects of buoyancy forces and jet momentum of horizontal fire are greater than that of the vertical fire. Moreover, the horizontal jet fire poses an interaction area smaller than that in the vertical fire [21]. The present study is convenient with the literature work [21], which revealed that the horizontal liquid fire was more serious than vertical liquid fire using a water mist-extinguishing agent.

\subsection{Discussion based on results of $\mathrm{S} / \mathrm{N}$ ratio response graphs}

Figure 3 shows the effects of release pressure on extinction time for vertical and horizontal LPG fire and corresponding $\mathrm{S} / \mathrm{N}$ ratio. With the release pressure increasing from $\mathrm{P} 1$ $(0.2 \mathrm{MPa})$ to $\mathrm{P} 3(0.4 \mathrm{MPa})$, the mean extinction time greatly dropped by $8.5 \%$ (from 0.257 to $0.237 \mathrm{~s}$ ) and $61.5 \%$ (from 0.399 to $0.247 \mathrm{~s}$ ) for vertical and horizontal fire, respectively. It is obvious that the influence of pressure on the horizontal fire suppression time was greater than that of the vertical fire suppression. These results were also confirmed by ANOVA, which found that the percentage contributions of pressure were $2.63 \%$ and $17.65 \%$ for the vertical and horizontal fire, respectively. The reason may be that the negative effect of the gravitational force on the vertical powder stream is less than that of the horizontal powder stream. Therefore, in horizontal suppression, the higher the release pressure, the higher the ability to overcome the gravitational effect and reach the flame faster with higher momentum; which in turn, reduce significantly the extinction time.

The influential mechanism of pressure can be explained as follows: the higher the release pressure, the larger the pressure drop (the difference between the $\mathrm{N}_{2}$ pressure at regulator outlet and the atmospheric pressure at the exit of powder nozzle), the higher the momentum, and the higher the exit velocity as seen in Table 12 .
Table 12 Exit velocity under various pressures

\begin{tabular}{llll}
\hline Release pressure (MPa) & 0.2 & 0.3 & 0.4 \\
Flow rate (L/s) & 0.15 & 0.21 & 0.28 \\
Exit velocity $(\mathrm{m} / \mathrm{s})$ & 0.59 & 0.83 & 1.1 \\
\hline
\end{tabular}

Therefore, the powder particles with higher velocity can reach the hot flame more rapidly with a strong capability to dilute the oxygen and flammable vapors inside the flame region. Thus, reducing the fire extinguishing time in comparing with a lower release pressure.

Besides, when the $\mathrm{N}_{2}$ release pressure increased, the flow rate of the powder stream increased. With a higher flow rate, a larger amount of powder was applied over time. Therefore, the isolation effect of powder and the interaction between powder particles and free radicals would more effective and suppression time would be less. Similar results were observed in past single effect studies of pressure on the extinction time for liquefied fires such as Ref. [11].

The effects of suppression angle on the extinction time of vertical and horizontal LPG fire and corresponding mean $\mathrm{S} / \mathrm{N}$ ratio are shown in Fig. 4 . It can be seen that the vertical suppression was the most effective suppression angle and followed by the horizontal suppression and then the diagonal suppression. The extinction time of vertical flame by vertical suppression was $28.5 \%$ and $45 \%$ lower than that of horizontal and diagonal suppression, respectively. Similarly, the extinction time of horizontal flame by vertical suppression was $3.5 \%$ and $62.7 \%$ less than that of horizontal and diagonal suppression angles, respectively. Moreover, from ANOVA, it was clearly apparent that the suppression angle has a larger effect on vertical fire suppression time (44.69\%) in comparing with horizontal fire (12.34\%). The effect of the suppression angle can be interpreted as follows.

In vertical suppression, the extinguishing powder reached and interacted with the boundary of the hot plume faster than that of horizontal and diagonal suppression angles (see Fig. 2). Besides, the acceleration gravity has a positive impact on powder particles in vertical suppression, which maintained their initial exit velocity and improved the penetration capability to the flame. While in horizontal and diagonal suppression, the gravitational force exerted a negative force on the powder stream, which pulled the powder particles downward along the distance from the nozzle to the fire. This may gradually reduce the velocity and momentum of the powder stream. As a result, the ability to dilute the flammable vapors became weaker than that of vertical suppression.

Figure 5 shows the effects of release distance on the extinction time of both fires. At shorter release distance 


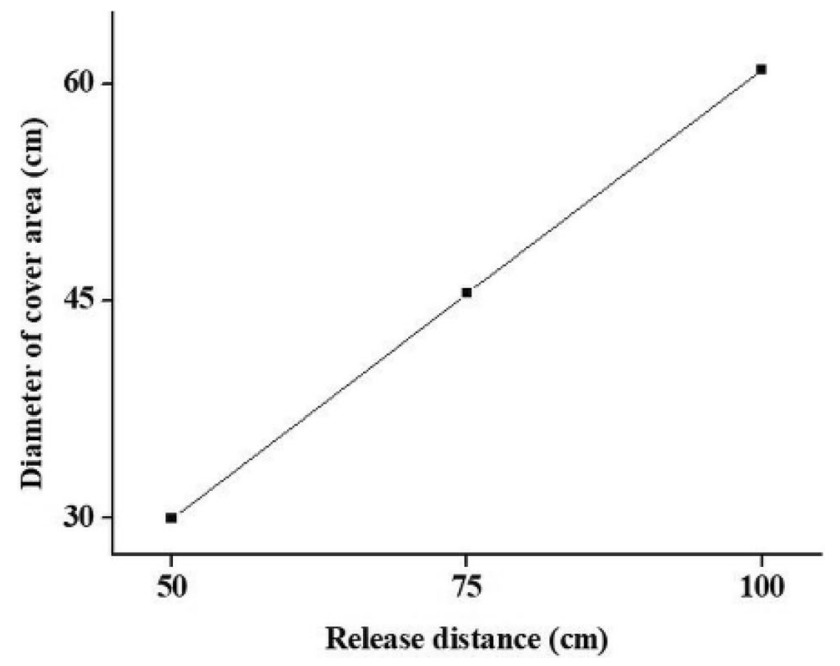

Fig. 8 Diameter of cover area over release distance

$(50 \mathrm{~cm})$, the mean extinction time was less for both fires in comparing with longer release distances. With an increase in release distance from 50 to $100 \mathrm{~cm}$, the mean extinction time increased by $43 \%$ and $172 \%$ for vertical and horizontal fire, respectively. It can be seen from ANOVA tables that the release distance exhibited superior contribution on horizontal fire suppression time $(66.00 \%)$ to the vertical fire suppression (39.04\%). When the release distance increased, the coverage area diameter of the powder stream increased. Figure 8 displays the coverage area diameter at different release distance values. When the release distance increased from 50 to $75 \mathrm{~cm}$ and $100 \mathrm{~cm}$, the cover area diameter increased from 30 to $45.5 \mathrm{~cm}$ and $61 \mathrm{~cm}$, respectively. Therefore, the powder stream covers a larger area. The momentum also decreased, and the time needed to reach the hot plume increased. This, in turn, reduced the powder's ability to penetrate, dilute and push the flame vapors and radicals away from the burning zone. Accordingly, the time to suppress the fire would be higher.

\section{Conclusions}

In this work, Taguchi OA design was employed to study and optimize the extinguishing process of the dry chemical powder system for small vertical and horizontal gaseous fires. The extinguishing process parameters involved the release pressure, the suppression angle, and the release distance. The main conclusions drawn from this experimental research can be summarized in the following points:

- The ANOM of $\mathrm{S} / \mathrm{N}$ ratios showed that the optimum extinguishing parameters for vertical and horizon- tal fires were at the highest level of release pressure $(0.4 \mathrm{MPa})$, the suppression angle (vertical), and the shortest release distance $(50 \mathrm{~cm})$.

- The ANOVA indicated that the suppression angle $(44.69 \%)$ was the most influencing factor on vertical fire extinction time. The release distance also showed a significant contribution (39.04\%). However, the release pressure showed a little contribution to extinction time (2.63\%).

- In the case of horizontal fire, it was found that the release distance was the dominant contributor $(66.00 \%)$ to extinction time, which was greater than that of vertical fire. The contribution of release pressure $(17.65 \%)$ was higher than that obtained in the vertical fire. While the suppression angle (12.34\%) had a less contribution in comparing with vertical fire.

- The confirmation extinguishing tests revealed that the extinction time at optimal parameters was less than that achieved in all other tests.

\section{Compliance with ethical standards}

Conflict of interest This research has no conflict of interest.

\section{Appendix}

- The LPG volumetric flow rate was measured as $1.1 * 10^{-4} \mathrm{~m}^{3} / \mathrm{s}$

- Mass flow rate $=$ volumetric flow rate $*=1.1 * 10^{-4 *} 2$. $2=0.00024 \mathrm{~kg} / \mathrm{s}$.

Where $\rho$ is a average LPG density.

$\bullet$

$$
\text { The exit velocity } \begin{aligned}
(\mu) & =\frac{\text { volumetric flow rate }}{\mathrm{A}} \\
& =\frac{1.1 * 10^{-4}}{2.8 * 10^{-5}}=3.93 \mathrm{~m} / \mathrm{s} .
\end{aligned}
$$

where $A$ represents the cross-section area of the LPG exit $\left(\mathrm{m}^{2}\right)$.

- The source Froude number:

$\mathrm{Fr}=\frac{\mathrm{u}^{2}}{\mathrm{gd}}=\frac{3.93^{2}}{9.81 * 0.006}=262.4$

where g represents the acceleration of gravity $(\mathrm{m} / \mathrm{s})$.

- Reynolds number:

$\operatorname{Re}=\frac{\rho \cdot d \cdot u}{\mu}=\frac{2.2 * 0.006 * 3.93}{7.5 * 10^{-6}}=6913$.

where $\mu$ represents the gas dynamic viscosity (Pa s).

- The thermal power of the LPG flame was estimated using the equation given by Rocha et al. (Rocha M, Pierrobon E, Panella L, Ferreira E, Simões-Moreir J 
(2010) Conversion methods for commercial stoves from LPG to natural gaas firing. In 13th Brazilian Congress of Thermal Sciences and Engineering-ENCIT, Uberlândia, Brazil, Dec (pp. 5-10).)

Nominal thermal power $=12.8 *$ Mass flow rate $(\mathrm{kg} / \mathrm{h})$ $=12.8 * 0.00024 * 3600=11.1 \mathrm{~kW}$.

\section{References}

1. Gopalaswami N, Liu Y, Laboureur DM, Zhang B, Mannan MS (2016) Experimental study on propane jet fire hazards: comparison of main geometrical features with empirical models. $J$ Loss Prev Process Ind 41:365-375

2. Gomez-Mares M, Zarate L, Casal J (2008) Jet fires and the domino effect. Fire Saf J 43(8):583-588

3. Zhao J, Suikkanen J, Wood M (2014) Lessons learned for process safety management in China. J Loss Prev Process Ind 29:170-176

4. Wang YF, Xie M, Ng KM, Habibullah MS (2011) Probability analysis of offshore fire by incorporating human and organizational factor. Ocean Eng 38(17-18):2042-2055

5. Stephen A, Karen M (1995) The history of Halon phase-out and regulation of Halon alternative. In: ACS symposium (Halon replacement), vol 15

6. Ni X, Kuang K, Yang D, Jin X, Liao G (2009) A new type of fire suppressant powder of $\mathrm{NaHCO}_{3} /$ zeolite nanocomposites with core-shell structure. Fire Saf J 44(7):968-975

7. Ni X, Kuang K, Wang X, Liao G (2010) A new type of BTP/zeolites nanocomposites as mixed-phase fire suppressant: preparation, characterization, and extinguishing mechanism discussion. J Fire Sci 28(1):5-25

8. Kuang K, Chow WK, Ni X, Yang D, Zeng W, Liao G (2011) Fire suppressing performance of superfine potassium bicarbonate powder. Fire Mater 35(6):353-366

9. Hu Y, Liu HQ, Zong RW, Lo SM (2018) Study of a new type of fire suppressant powder of $\mathrm{Mg}(\mathrm{OH})_{2}$ modified by DOPO-VTS. Procedia Eng 211:1102-1110

10. Kuang K, Huang X, Liao G (2008) A comparison between superfine magnesium hydroxide powders and commercial dry powders on fire suppression effectiveness. Process Saf Environ Prot 86(3):182-188

11. Du D, Shen X, Feng L, Hua M, Pan X (2019) Efficiency characterization of fire extinguishing compound superfine powder containing $\mathrm{Mg}(\mathrm{OH})_{2}$. J Loss Prev Process Ind 57:73-80

12. Shi B, Zhou $F$ (2016) Fire extinguishment behaviors of liquid fuel using liquid nitrogen jet. Process Saf Prog 35(4):407-413

13. Liu Z, Kim AK, Carpenter D (2007) A study of portable water mist fire extinguishers used for extinguishment of multiple fire types. Fire Saf J 42(1):25-42

14. Lin CL (2004) Use of the Taguchi method and grey relational analysis to optimize turning operations with multiple performance characteristics. Mater Manuf Process 19(2):209-220

15. Taguchi $G$ (1986) Introduction to quality engineering: designing quality into products and processes (No. 658.562 T3)

16. Taguchi G, Chowdhury S, Wu Y (2005) Taguchi's quality engineering handbook. Wiley, New York

17. Yang WP, Tarng YS (1998) Design optimization of cutting parameters for turning operations based on the Taguchi method. J Mater Process Technol 84(1-3):122-129

18. Selvaraj DP, Chandramohan P, Mohanraj M (2014) Optimization of surface roughness, cutting force and tool wear of nitrogen alloyed duplex stainless steel in a dry turning process using Taguchi method. Measurement 49:205-215

19. Taguchi G, Phadke MS (1989) Quality engineering through design optimization. In: Dehnad K (ed) Quality control, robust design, and the Taguchi method. Springer, Boston, pp 77-96

20. Gaitonde VN, Karnik SR, Davim JP (2008) Prediction and optimization of surface roughness in milling of medium density fiberboard (MDF) based on Taguchi orthogonal array experiments. Holzforschung 62(2):209-214

21. Liang T, Liu M, Wei X, Zhong W (2014) An experimental study on the interaction of water mist with vertical/horizontal spray flame. Procedia Eng 84:543-552

Publisher's Note Springer Nature remains neutral with regard to jurisdictional claims in published maps and institutional affiliations. 